Research Article

\title{
Photocatalytic Degradation of Methylene Blue from Aqueous Medium onto Perlite-Based Geopolymer
}

\author{
Hamid Saufi $(\mathbb{D}$, Marouane El Alouani $\mathbb{D}$, Saliha Alehyen, Mohammed El Achouri, \\ Jilali Aride, and M'hamed Taibi
}

Mohammed V University in Rabat, Laboratoire de Physico-Chimie des Matériaux Inorganiques et Organiques (LPCMIO), Ecole Normale Supérieure (ENS), Centre des Sciences des Matériaux (CSM), Rabat, Morocco

Correspondence should be addressed to Marouane El Alouani; ma.elalouani@gmail.com

Received 17 September 2019; Revised 15 January 2020; Accepted 20 January 2020; Published 14 February 2020

Academic Editor: Antonio Brasiello

Copyright (C) 2020 Hamid Saufi et al. This is an open access article distributed under the Creative Commons Attribution License, which permits unrestricted use, distribution, and reproduction in any medium, provided the original work is properly cited.

In this work, geopolymer synthesized with perlite and an alkaline activator medium was evaluated as a new adsorbent and photocatalyst for degradation of methylene blue (MB) dye from an aqueous medium. The functional group, the structure, and the morphology of the raw and the synthesized materials were characterized using FT-IR, XRD, and SEM analysis. The degradation of $\mathrm{MB}$ in the contaminated solution was examined using the spectrophotometric technique. Several analysis methods revealed the formation of the aluminosilicate gel after the geopolymerization reaction. The kinetics data with UV and without UV irradiations were well fitted with the pseudo-second-order equation. The results indicated that the degradation efficiency of cationic dye by perlite-based geopolymer without and with UV was up to $88.94 \%$ and $97.87 \%$ in 4 hours, respectively. The degradation efficiencies of methylene blue are in the following order: perlite-based geopolymer under UV irradiations is greater than perlite-based geopolymer without UV irradiations that is larger than UV irradiations. The overall experimental results suggested that the new elaborated material with synergetic adsorption and photocatalytic activities has a great potential for the treatment of water contaminated by hazardous substances.

\section{Introduction}

One of the major water-consuming industries in the world is the textile one, with an average of 1.6 million liters of water per day [1]. The textile industry uses a variety of chemical compounds that pollute water, such as dyes, heavy metals, and surfactants. The previously cited compounds are hazardous and hard to deteriorate. This makes them even more dangerous to the environment, which is why it needs to be removed from wastewaters before discharge in the aqueous system. Several wastewater treatment techniques such as ultrafiltration [2], membrane separation [3], ion exchange [4], coagulation/flocculation [5], electrochemical processes [6], adsorption [7, 8], and photocatalytic degradation [9] have been used to remove and degrade the dyes from water and wastewater. The photocatalytic degradation method is based on the degradation of organic pollutants in the presence of UV and a material doped by a photocatalyst.
$\mathrm{TiO}_{2}$ and $\mathrm{ZnO}$ are the most efficient photocatalyst materials used for degradation of organic pollutants from water and wastewaters [10]. The photodegradation technique presents a problem to eliminate products formed in the aquatic environment after photocatalytic degradation process. In the last years, several research studies have been focused on the synthesis of materials generally obtained by dispersing photocatalysts in natural materials or synthetic origin and developed the matrices rich by photocatalytics. These matrices have good chemical and physical properties, high degradation and adsorption capacities of organic pollutants, and ease of use and respects the environmental system. During the last decade, many studies have been focused on the organic pollutant degradation onto formed materials such as organic-inorganic hybrid nanocomposites [11], chitosan-gelatin-based hydrogel [12], $\mathrm{Gd}_{-} \mathrm{TiO}_{2}-\mathrm{GO}$ nanocomposites [13], graphene/geopolymer nanocomposites [14], and fly ash-based geopolymer [9]. Among them, the 
materials synthesized in this technique are geopolymers which are the inorganic polymers synthesized by aluminosilicate precursors. They can be natural (perlite, clay, etc.) or synthetic (fly ash, metakaolin, etc.) materials activated by alkaline activator solutions at a temperature below $100^{\circ} \mathrm{C}$ [15]. These materials used as adsorbents can adsorb harmful organic substances from the aquatic environment. The organic pollutant molecules adsorbed on the surface of these synthesized materials were not degraded. In order to resolve this issue, UV irradiation can be used since it is able to degrade the molecules that remain in the solution and adsorbed on the surface of the matrices. This study aimed to elaborate a perlite-based geopolymer using expanded perlite and alkali solution. The obtained material was valued as the photocatalyst and an adsorbent for the degradation and the removal of the MB dye from aqueous media. The raw and synthesized materials were analyzed by FTIR, DRX, and SEM methods. The kinetics studies were performed to evaluate the adsorption-photodegradation synergetic mechanism for the removal of MB using the perlite-based geopolymer catalyst.

\section{Materials and Methods}

2.1. Materials. The chemical reagents, used in all experiments, were sodium hydroxide $(\mathrm{NaOH})$ (with $99 \%$ purity, from Sigma-Aldrich) and sodium hydroxide (with 99\% purity, from Sigma-Aldrich). Methylene blue was purchased from Sigma-Aldrich. The expanded perlite was obtained from Chemviron, Belgium. This powder was sieved by an $80 \mu \mathrm{m}$ strainer and dried at $105^{\circ} \mathrm{C}$ for $24 \mathrm{~h}$. The chemical composition in weight percent of the expanded perlite is presented in Table 1.

2.2. Synthesis Method. The perlite-based geopolymer was synthesized similar to the methods mentioned in previous investigations $[16,17]$. The alkali activator solution was produced by mixing sodium silicate and $\mathrm{NaOH}$ solution $(12 \mathrm{M})$ with a 2.5 ratio at room temperature for $15 \mathrm{~min}$. The perlite powder was added and mixed with a prepared solution with 2.5 ratio at ambient temperature for $15 \mathrm{~min}$. The paste was introduced into a cylindrical mold and heated at $60^{\circ} \mathrm{C}$ for $24 \mathrm{~h} \mathrm{[18]}$. The obtained specimen was dried at room temperature for 3 days. For the degradation and the photodegradation tests, the obtained material was ground and sieved to a particle size of less than $200 \mu \mathrm{m}$.

2.3. Characterization of Samples. The structure of the raw material and the prepared composite was obtained using an $\mathrm{X}$-ray diffractometer (Xpert Pro model). The microstructure of the samples was studied using a scanning electron microscope (JEOL-6300, field with an accelerating voltage of $15 \mathrm{kV})$. The functional groups of materials were detected using a Bruker Alpha Platinum-ATR apparatus infrared spectrophotometer. The UV-Vis spectrum of the synthesized composite was recorded in a JASCO V-630 UV-Vis-NIR spectrophotometer. The absorbance of the solution was measured using a JASCO V-630 UV/VIS spectrophotometer.
2.4. Adsorption and Photodegradation Test. The adsorption and photodegradation phenomena were evaluated by monitoring the efficiency degradation of organic compound methylene blue in aqueous solution using the perlite-based geopolymer. The photocatalytic processes were conducted out in the photocatalytic reactor and were carried out under similar conditions $\left(C_{\mathrm{i}}=30 \mathrm{mg} / \mathrm{L}, \mathrm{pH}=5\right)$. In our work, $0.1 \mathrm{~g}$ of the perlite-based geopolymer photocatalyst was added into a reactor that was filled with $100 \mathrm{~mL}$ of aqueous media contaminated by methylene blue of $30 \mathrm{mg} / \mathrm{L}$. The reaction suspension was stirred at a constant speed $(250 \mathrm{rpm})$. The ultraviolet light source was supplied by a mercury lamp of the Osram HQL 125WE27 type emitting a wavelength between 254 and $380 \mathrm{~nm}$. At given time intervals, the reaction mixture was centrifuged in a centrifuge (ROTOFIX 32A) to separate the supernatant (catalyst particles) and the polluted solution. The filtrates were characterized with a UV-Vis spectrophotometer at a maximum absorption wavelength of $665 \mathrm{~nm}$. The degradation efficiency was determined from the following equation [19]:

$$
\text { degradation efficiency }(\%)=\frac{A_{0}-A_{t}}{A_{0}} \times 100=\frac{C_{0}-C_{t}}{C_{0}} \times 100 \text {. }
$$

$A_{0}$ and $A_{t}$ are the initial absorbance and absorbance of dye at time $t$ and $\mathrm{C}_{0}$ and $\mathrm{C}_{t}$ are the initial concentration and concentration of dye at time $t(\mathrm{mg} / \mathrm{L})$.

2.5. Data Analysis. In this work, the pseudo-first-order, pseudo-second-order kinetic, and intraparticle diffusion models [18] were investigated to study the nature of the adsorption of the methylene blue molecules using the perlite-based geopolymer. Table 2 displays the equations and mathematical parameters of kinetic models.

\section{Results and Discussion}

\subsection{Morphology and Structure of Samples}

3.1.1. XRD Analysis. The X-ray diffraction patterns (XRD) were used to reveal the structure existing in perlite before and after the geopolymerization process. The X-ray diffraction patterns (XRD) of the perlite and synthesized material are exhibited in Figure 1. As shown, perlite is essentially consisting of amorphous mineral phases observed between $10^{\circ}$ and $40^{\circ}(2 \theta)$. After the geopolymerization reaction, the amorphous dump or halo has shifted to higher angles from 20 to $42^{\circ}(2 \theta)$. This shifting reveals the formation of the new amorphous alumino-silicate phase in the geopolymer structure [20].

3.1.2. FTIR Analysis. FTIR analysis was used to indicate the functional groups existing in the raw material before and after activation. The FT-IR spectra of the samples are given in Figure 2. For perlite, the band located at $1632 \mathrm{~cm}^{-1}$ is assigned to the vibration of $\mathrm{OH}$ groups. The large band observed at $1005 \mathrm{~cm}^{-1}$ is assigned to the stretching vibrations of Si-O-M $(M=\mathrm{Al}$ or $\mathrm{Si})$ [21]. The band located at 
TABLe 1: Quantitative chemical composition of perlite (wt.\%).

\begin{tabular}{lcccccccc}
\hline Major elements & $\mathrm{SiO}_{2}$ & $\mathrm{Al}_{2} \mathrm{O}_{3}$ & $\mathrm{Na}_{2} \mathrm{O}$ & $\mathrm{K}_{2} \mathrm{O}$ & $\mathrm{Fe}_{2} \mathrm{O}_{3}$ & $\mathrm{CaO}$ & $\mathrm{MgO}$ & $\mathrm{TiO}$ \\
\hline Composition (wt.\%) & 74.75 & 12.48 & 4.48 & 5.42 & 0.88 & 0.7 & 0.1 & 0.06 \\
\hline
\end{tabular}

TABLE 2: The equations and their plot parameters of kinetic models.

\begin{tabular}{|c|c|c|}
\hline Kinetic models & Equations & Plot parameters \\
\hline Pseudo-first-order & $\operatorname{Ln}\left(q_{e}-q_{t}\right)=\operatorname{Ln} q_{e}-k_{1} t$ & $q_{e}(\mathrm{mg} / \mathrm{g}):$ the adsorption capacity at equilibrium \\
\hline Pseudo-second-order & $\left(t / q_{t}\right)=\left(1 / k_{2} q_{e}^{2}\right)+\left(t / q_{e}\right)$ & $q_{t}(\mathrm{mg} / \mathrm{g})$ : the adsorption capacity at time $t(\mathrm{~min})$ \\
\hline Intraparticle diffusion model & $q_{t}=k_{I} t^{1 / 2}+I$ & $\begin{array}{c}k_{2}(\mathrm{~g} / \mathrm{mg} \mathrm{min}): \text { the pseudo-second-order rate constant } \\
k_{\mathrm{I}}(\mathrm{mg} /(\mathrm{g} \cdot \mathrm{min} 1 / 2)): \text { the intraparticle diffusion rate constant } \\
I(\mathrm{mg} / \mathrm{g}): \text { the intercept }\end{array}$ \\
\hline
\end{tabular}

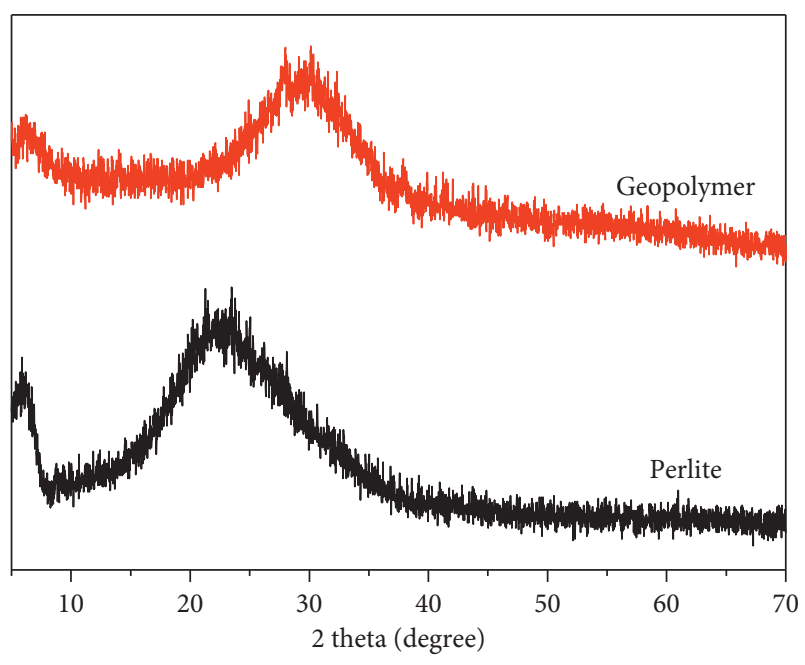

Figure 1: XRD analysis of perlite and the obtained geopolymer.

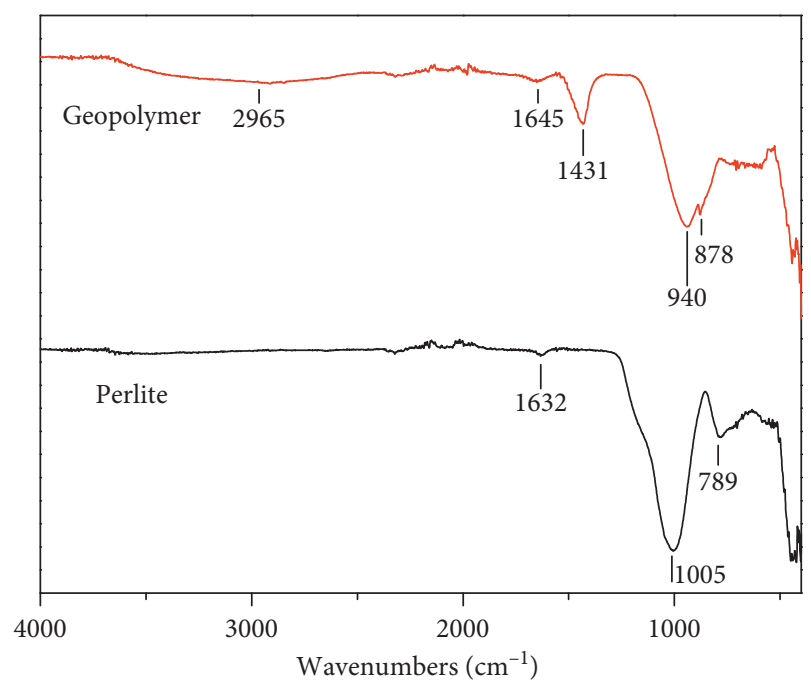

FIGURE 2: FT-IR analysis of perlite and geopolymer.

$789 \mathrm{~cm}^{-1}$ was attributed to $\mathrm{Si}-\mathrm{O}$ stretching vibration of $\mathrm{Si}-$ $\mathrm{O}-\mathrm{Al}$ [22]. After activation of the perlite by alkaline solution, new bands are observed at 2965 and $1645 \mathrm{~cm}^{-1}$ due to the presence of water molecules in the material structure.
The band located at $1431 \mathrm{~cm}^{-1}$ is attributed to antisymmetric vibrations of $\mathrm{CO}_{2}{ }^{3-}$ ions, revealing that sodium carbonate is present in the structure of the geopolymer [21]. The absorption band at $878 \mathrm{~cm}^{-1}$ is related to $\mathrm{Si}-\mathrm{O}-\mathrm{Al}$ stretching vibration. The stretching vibration of $\mathrm{Si}-\mathrm{O}-\mathrm{M}$ $(M=\mathrm{Al}$ or $\mathrm{Si})$ at $1005 \mathrm{~cm}^{-1}$ in perlite shifted approximately $65 \mathrm{~cm}^{-1}$ after the activation process to $940 \mathrm{~cm}^{-1}$. The shifting and reduction of the large band of the raw material after activation of perlite are due to the dissolution of the perlite particles by the alkaline solution and the formation of the geopolymer material. These results are confirmed by XRD analysis.

3.1.3. SEM Analysis. SEM micrographs of the perlite and perlite-based geopolymer are shown in Figure 3 . The structure of the raw material (Figure 3(a)) can be described as irregular particles with broken or ragged edges and flakelike form [23]. SEM image of activated perlite is presented in Figure 3(b). This micrograph revealed the formation of aluminosilicate gel in the perlite structure. This change in the perlite morphology indicates the dissolution of the precursor particles by alkali solution and the formation of aluminosilicate gel in the structure of the raw material [24].

3.1.4. Optical Study. The absorbance spectrum of the asprepared sample is depicted in Figure 4. The optical band gap energy $\left(E_{g}\right)$ was estimated based on absorbance data, as proposed by Wood and Tauc $[25,26]$. According to Tauc equation, the optical absorption coefficient $(\alpha)$ is related to the energy band gap by

$$
(\alpha h v)=A\left(h v-E_{g}\right)^{n},
$$

where $A$ is a constant of proportionality depending on the material, $h v$ is the photon energy, and $n$ is a constant that depends on the nature of the transition ( 2 for an indirect allowed transition and 1/2 for a direct allowed transition). The sample is found to depict an indirect optical band gap, and the extrapolation of the $(\alpha h v)^{0.5}$ vs. $h v$ slope (inset of Figure 4) to the zero value of $(\alpha h \nu)^{0.5}$ gives an indirect optical band gap energy of $3.82 \mathrm{eV}$, affirming the semiconductor behavior of the sample [27, 28]. 


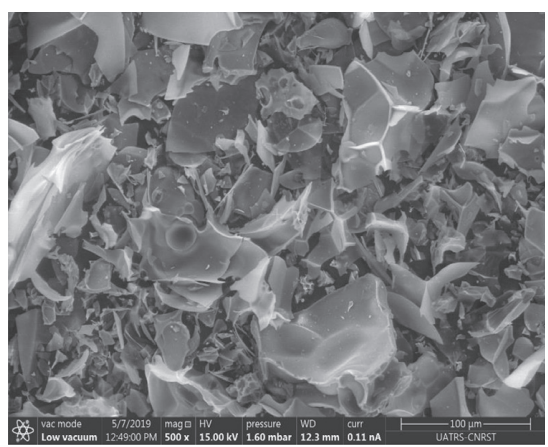

(a)
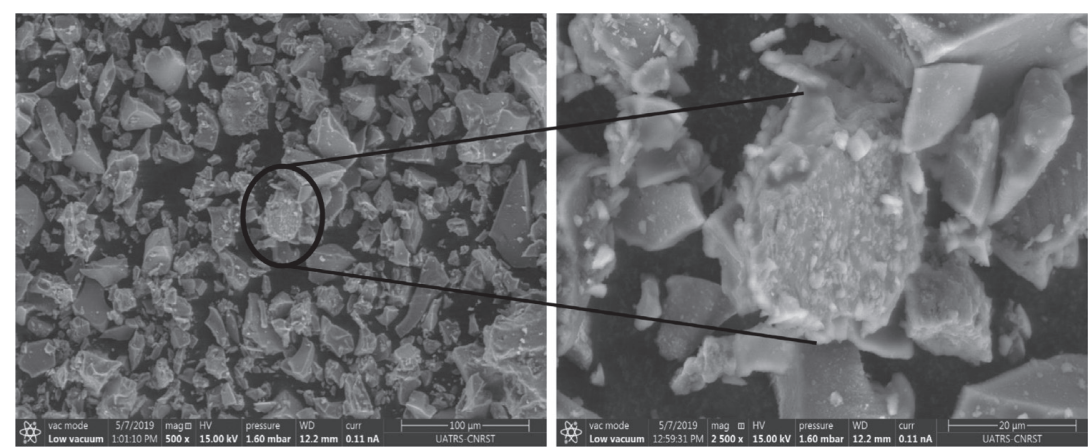

(b)

Figure 3: SEM images of (a) perlite and (b) geopolymer.

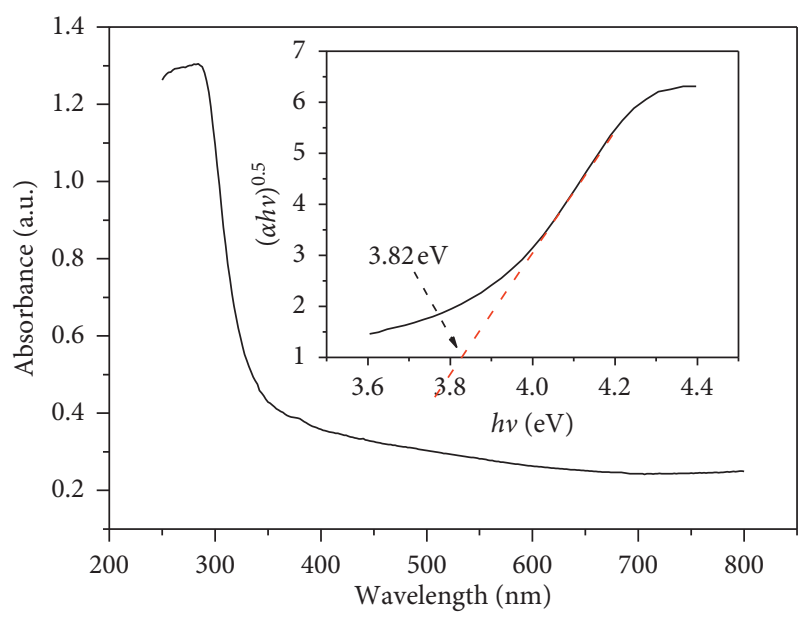

FIGURE 4: UV-visible absorbance spectra and the corresponding Tauc plot (inset) of the perlite-based geopolymer.

3.2. Degradation of Methylene Blue with UV. The study of the degradation of methylene blue in the aqueous solution by UV irradiation is presented in Figure 5. The results obtained from the variation in the absorbance of the pollutant over time show that the degradation of methylene blue by UV irradiation passed through series of decomposition. The first reaction is the oxidation of water molecules by UV irradiation to form hydroxyl radicals $(\bullet \mathrm{OH})$. These radicals then attacked the N-S heterocyclic chromophore group and form intermediate products after series of reactions [9]. These obtained products were degraded and conducted to simple products such as $\mathrm{H}_{2} \mathrm{O}$ and $\mathrm{CO}_{2}[29,30]$. Similar result was reported by Lin et al. [31].

3.3. Degradation of $M B$ Dye at Different Conditions. To evaluate the photodegradation and degradation of $\mathrm{MB}$ dye by the perlite-based geopolymer, three experimental processes are carried out as presented in Figure 6. The first part of the experiments is to follow the degradation of $\mathrm{MB}$ alone in the solution under UV excitation. The second part is focused on the study of the adsorption of this pollutant in the presence of the geopolymer without UV irritation. The last step is dedicated to the investigation of the adsorption of

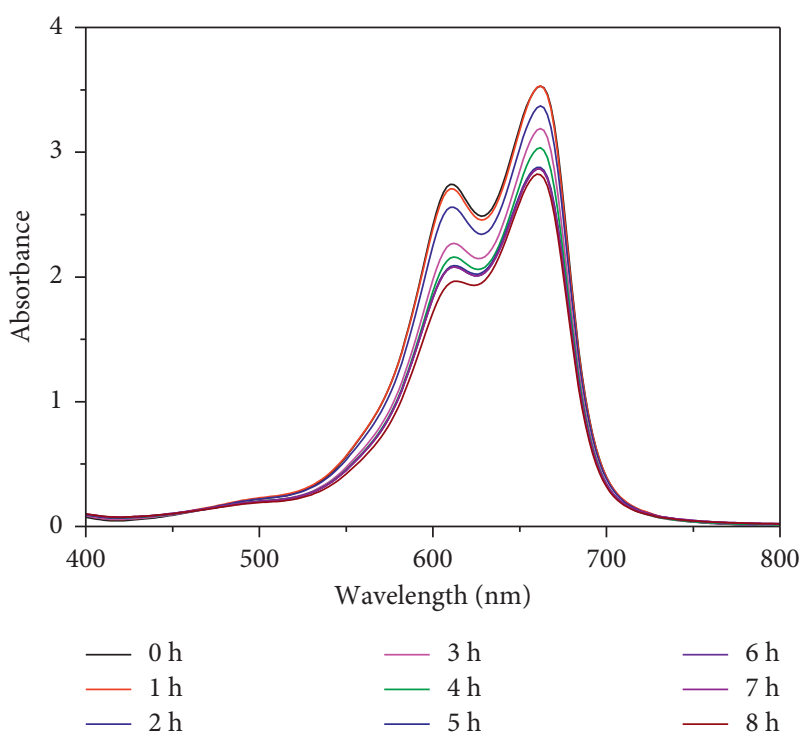

Figure 5: Absorbance spectrum of dye versus wavelength.

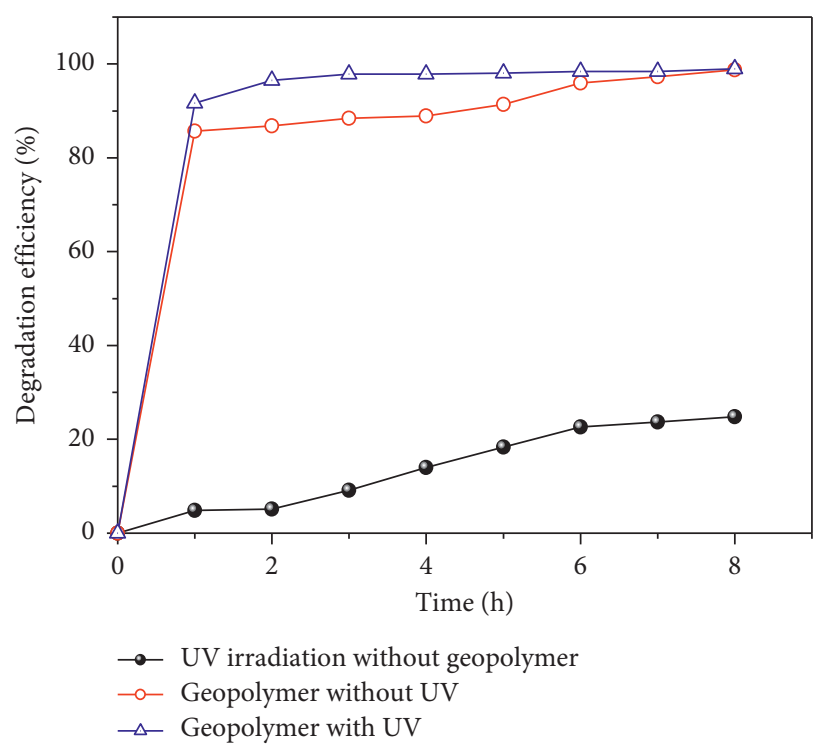

FIgURE 6: Photocatalytic degradation efficiencies of MB dye at different conditions. 


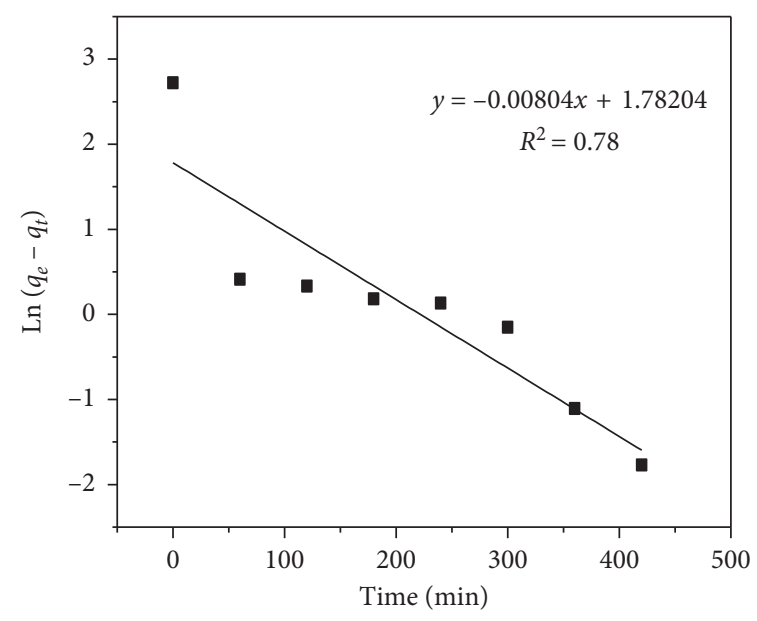

(a)

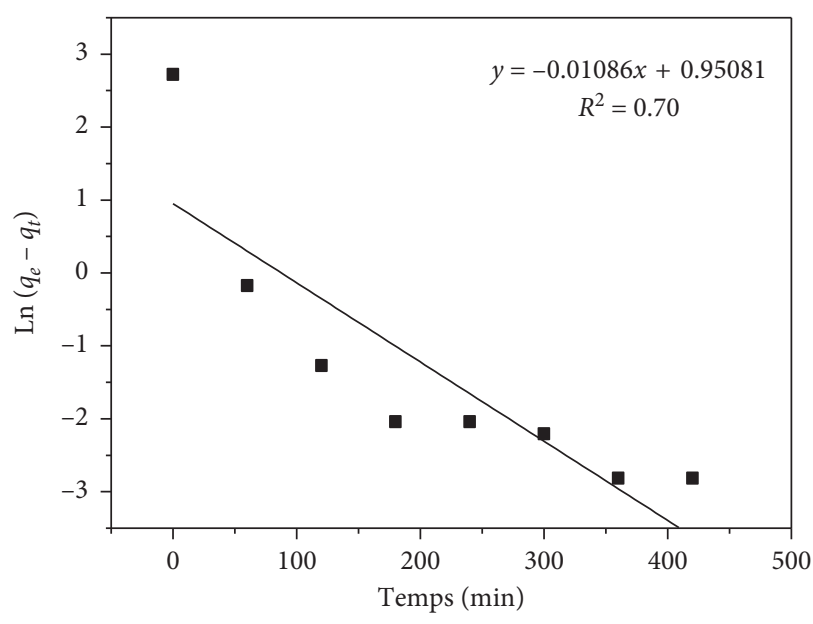

(b)

FIgURE 7: Plots of the first-order kinetics of MB dye adsorption on the geopolymer (a) without UV and (b) with UV.

methylene blue by the geopolymer in the presence of UV irradiation. When the aqueous solution contaminated by MB is exposed to UV irradiation without a perlite-based geopolymer photocatalyst, the degradation efficiency rate is as low as $14.02 \%$ for $4 \mathrm{~h}$. The second approach shows a high degradation efficiency (88.94\%) of the dye removal by the synthesized product without UV for $4 \mathrm{~h}$. The last approach indicated the highest degradation efficiency $(97.87 \%)$ of dye removal by the formed material catalytic under UV for $4 \mathrm{~h}$. This mechanism of the photocatalytic reaction process can be presented as follows. Firstly, the organic pollutant can ionize as a cationic product in the aqueous medium, and then the cations are adsorbed on the perlite-based geopolymer structure surface, as presented in equations (3) and (4). When the metal oxide semiconductor particles of $\mathrm{Fe}_{2} \mathrm{O}_{3}$ in the raw material (in Table 1) are irradiated by UV, the excited electron $\left(\mathrm{e}^{-}\right)$and hole $\left(\mathrm{h}^{+}\right)$pairs are formed, as presented in equation (5). Subsequently, the transition metal ions of $\mathrm{Fe}^{3+}$ in the material ensnare electron $\left(\mathrm{e}^{-}\right)$and hole $\left(\mathrm{h}^{+}\right)$combine with $\mathrm{H}_{2} \mathrm{O}$ molecule to produce hydroxyl radical (equations (6) and (7)). Finally, the cations of MB dye adsorbed on the framework of the perlite-based geopolymer are oxidized by hydroxyl radicals to form the degradation products in equation (8). By comparing the experimental results, it can be seen that the degradation efficiency of MB which is of the order of the geopolymer with UV irradiations is greater than the adsorption by the geopolymer without UV irradiations which is larger than UV irradiations without the geopolymer (direct photolysis).

The perlite-based geopolymer, associated with UV radiations, possesses better adsorption and photodegradation properties for methylene blue molecules than the perlite-based geopolymer without UV. This performance is due to the synergetic effect rather than simple linear combination of the perlite-based geopolymer powder and UV irradiation for removal of methylene blue from aqueous solution.

$$
\begin{aligned}
\mathrm{MB}+\mathrm{H}_{2} \mathrm{O} & \longrightarrow \mathrm{MB}^{+}+\mathrm{Cl}^{-} \\
\mathrm{MB}^{+}+\left(-\mathrm{Si}-\mathrm{O}-\mathrm{Al}^{-}-\mathrm{O}-\mathrm{Si}-\right)_{n} & \longrightarrow\left(-\mathrm{Si}-\mathrm{O}-\mathrm{Al}^{-}-\mathrm{O}-\mathrm{Si}-\right)_{n} \\
& \longrightarrow \mathrm{Fe}_{2} \mathrm{O}_{3}\left(\mathrm{~h}^{+}\right)+\mathrm{e}^{-} \\
\mathrm{Fe}_{2} \mathrm{O}_{3} & \longrightarrow \mathrm{Fe}^{2+} \\
\mathrm{Fe}^{3+}+\mathrm{e}^{-} & \longrightarrow \mathrm{H}^{+}+{ }^{\circ} \mathrm{OH} \\
\mathrm{h}^{+}+\mathrm{H}_{2} \mathrm{O} & \longrightarrow \mathrm{CO}_{2}+\mathrm{H}_{2} \mathrm{O} \\
\mathrm{MB}+{ }^{\circ} \mathrm{OH} &
\end{aligned}
$$

3.4. Adsorption Kinetics. Adsorption kinetic was used to characterize the nature of the adsorption process between adsorbent and adsorbate. The kinetic models of methylene blue onto the perlite-based geopolymer were evaluated by three kinetic equations (Table 2). The experimental results of $\mathrm{MB}$ adsorption by the perlite-based geopolymer with and without UV irradiation are presented in Figures 7-9. The kinetic parameters and the determined coefficients are depicted in Table 3. The correlation coefficients by the pseudo-second-order equation are closer and more accurate compared with pseudo-first-order and intraparticle diffusion equations. The calculated $q_{e}$ values $(15.51 \mathrm{mg} / \mathrm{g}$ under UV and $15.28 \mathrm{mg} / \mathrm{g}$ without UV) were close to the observed experimental values ( $q_{e, \text { exp }}=15.18 \mathrm{mg} / \mathrm{g}$ under UV and $15.20 \mathrm{mg} / \mathrm{g}$ without UV), respectively. This result revealed that the adsorption of $\mathrm{MB}$ dye by the perlite-based geopolymer under UV and without UV is following by the pseudo-second-order model. This kinetic model confirms that the adsorption process is based on chemisorption. This phenomenon can be explained by the interaction between the negatively charged adsorbent and the positively charged adsorbate [18]. 


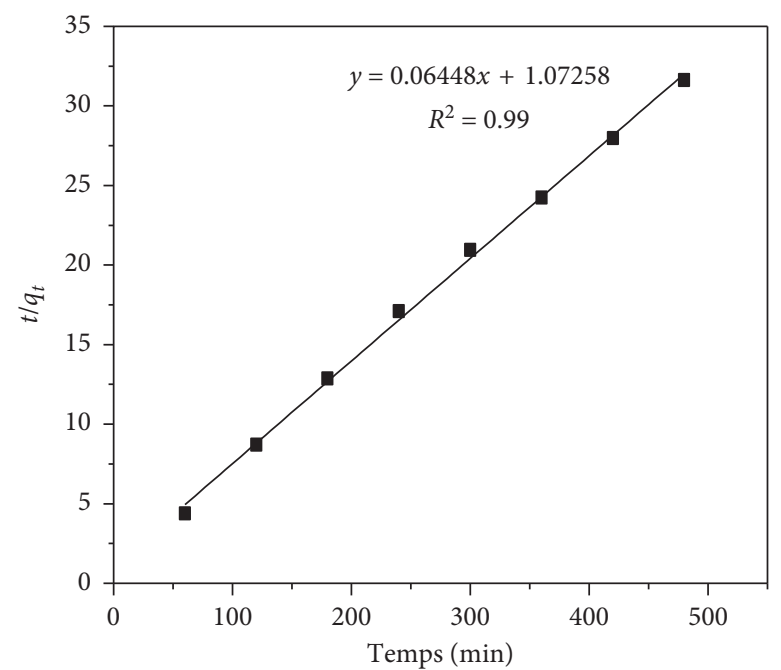

(a)

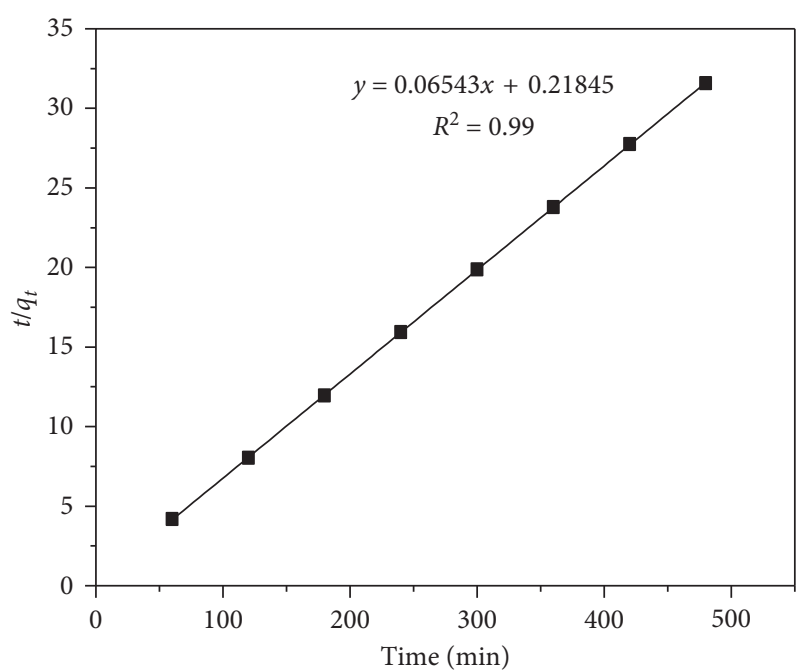

(b)

FIgURE 8: Plots of the pseudo-order kinetics of MB dye adsorption on the geopolymer (a) without UV and (b) with UV.

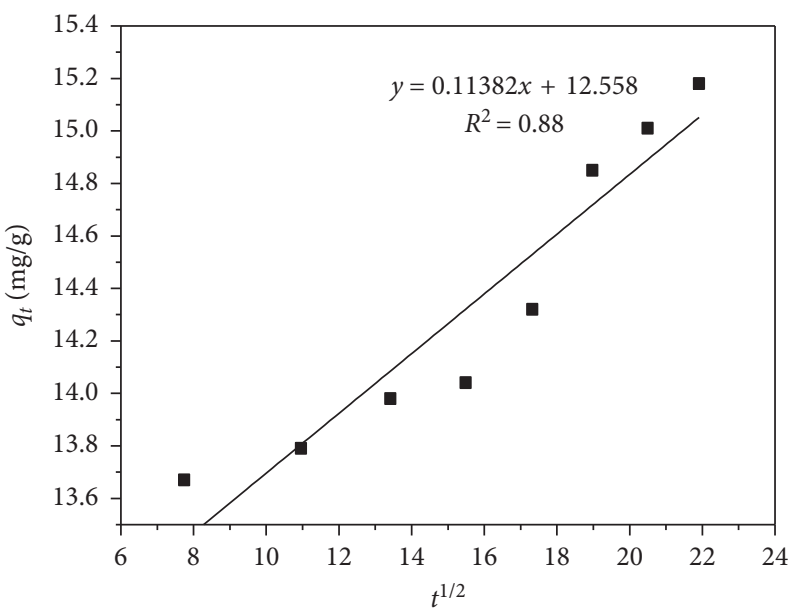

(a)

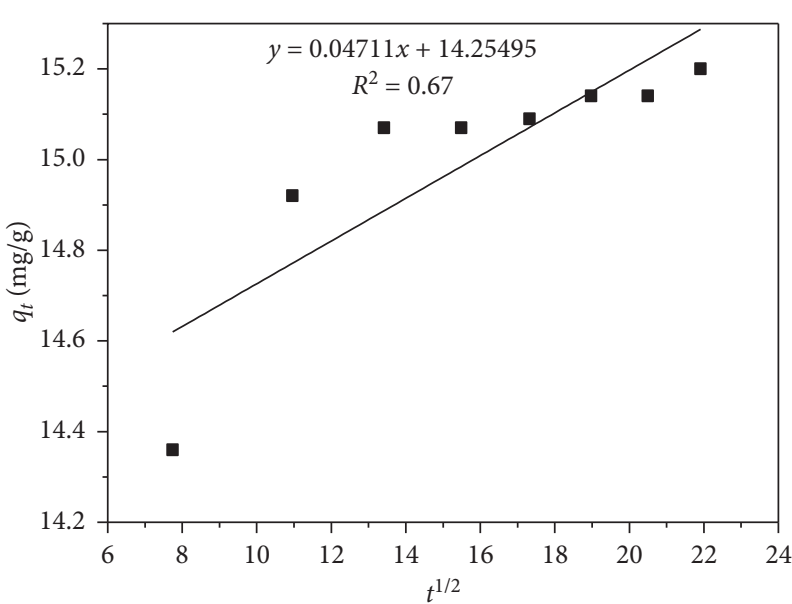

(b)

FIgURE 9: Plots of the intraparticle kinetics of MB dye adsorption on the geopolymer (a) without UV and (b) with UV.

TABle 3: Parameters of kinetics models for the adsorption of MB on the geopolymer.

\begin{tabular}{lcccccccccc}
\hline \multirow{2}{*}{ Condition } & \multirow{2}{*}{$q_{\mathrm{ex}}(\mathrm{mg} / \mathrm{g})$} & \multicolumn{2}{c}{ Pseudo-first-order } & \multicolumn{2}{c}{ Pseudo-second-order } & \multicolumn{3}{c}{ Intraparticle diffusion } \\
& & $k_{1}\left(\mathrm{~min}^{-1}\right)$ & $q_{e}(\mathrm{mg} / \mathrm{g})$ & $R^{2}$ & $k_{2}(\mathrm{~g} /(\mathrm{mg} \mathrm{min}))$ & $q_{e}(\mathrm{mg} / \mathrm{g})$ & $R^{2}$ & $k_{p}\left(\mathrm{mg} /\left(\mathrm{g} \mathrm{min}{ }^{1 / 2}\right)\right)$ & $I$ & $R^{2}$ \\
\hline Without UV & 15.18 & 0.008 & 5.94 & 0.78 & 0.004 & 15.51 & 0.99 & 0.118 & 12.60 & 0.88 \\
With UV & 15.20 & 0.011 & 2.59 & 0.70 & 0.020 & 15.28 & 0.99 & 0.047 & 14.30 & 0.67 \\
\hline
\end{tabular}

\section{Conclusion}

The geopolymer produced by the alkali activator and perlite is used as an adsorbent and photocatalyst and for degradation of cationic dye in aqueous media. The analysis by several methods revealed the formation of a new photocatalyst product. The kinetic data of the removal of dyestuff on the surface of the synthesized material were fitted by the pseudo-second-order model. The results obtained in this study suggest that the perlite-based geopolymer could be used as an efficient adsorbent and photocatalytic for the treatment of methylene blue contaminants in aqueous media.

\section{Data Availability}

The data used to support the findings of this study are available from the corresponding author upon request.

\section{Conflicts of Interest}

The authors declare that they have no conflicts of interest. 


\section{References}

[1] D. Dadi, T. Stellmacher, F. Senbeta, S. Van Passel, and H. Azadi, "Environmental and health impacts of effluents from textile industries in Ethiopia: the case of Gelan and Dukem, Oromia regional state," Environmental Monitoring and Assessment, vol. 189, no. 1, p. 11, 2017.

[2] M. Jiang, K. Ye, J. Lin et al., "Effective dye purification using tight ceramic ultrafiltration membrane," Journal of Membrane Science, vol. 566, pp. 151-160, 2018.

[3] H. Liu, Y. Chen, K. Zhang et al., "Poly(vinylidene fluoride) hollow fiber membrane for high-efficiency separation of dyessalts," Journal of Membrane Science, vol. 578, pp. 43-52, 2019.

[4] J. Pan, D. Zhang, M.-M. Shang, Y. Mu, S.-D. Han, and G.-M. Wang, "An anionic Cd-based coordination polymer exhibiting ion-exchange behavior for photoluminescence and selective dye adsorption," Journal of Luminescence, vol. 210, pp. 70-74, 2019.

[5] N. d. C. L. Beluci, G. A. P. Mateus, C. S. Miyashiro et al., "Hybrid treatment of coagulation/flocculation process followed by ultrafiltration in $\mathrm{TIO}_{2}$-modified membranes to improve the removal of reactive black 5 dye," Science of the Total Environment, vol. 664, pp. 222-229, 2019.

[6] N. P. Shetti, S. J. Malode, R. S. Malladi, S. L. Nargund, S. S. Shukla, and T. M. Aminabhavi, "Electrochemical detection and degradation of textile dye Congo red at graphene oxide modified electrode," Microchemical Journal, vol. 146, pp. 387-392, 2019.

[7] M. E. Alouani, S. Alehyen, M. E. Achouri, and M. Taibi, "Comparative studies on removal of textile dye onto geopolymeric adsorbents," EnvironmentAsia, vol. 12, pp. 143-153, 2019.

[8] M. El Alouani, S. Alehyen, M. El Achouri, and M. Taibi, "Adsorption of cationic dye onto fly ash-based geopolymer: batch and fixed bed column studies," MATEC Web of Conferences, vol. 149, p. 02088, 2018.

[9] Y. Zhang and L. Liu, "Fly ash-based geopolymer as a novel photocatalyst for degradation of dye from wastewater," Particuology, vol. 11, no. 3, pp. 353-358, 2013.

[10] R. Raliya, C. Avery, S. Chakrabarti, and P. Biswas, "Photocatalytic degradation of methyl orange dye by pristine titanium dioxide, zinc oxide, and graphene oxide nanostructures and their composites under visible light irradiation," Applied Nanoscience, vol. 7, no. 5, pp. 253-259, 2017.

[11] K. Kaur and R. Jindal, "Synergistic effect of organic-inorganic hybrid nanocomposite ion exchanger on photocatalytic degradation of rhodamine-B dye and heavy metal ion removal from industrial effluents," Journal of Environmental Chemical Engineering, vol. 6, no. 6, pp. 7091-7101, 2018.

[12] K. Kaur and R. Jindal, "Comparative study on the behaviour of Chitosan-Gelatin based hydrogel and nanocomposite ion exchanger synthesized under microwave conditions towards photocatalytic removal of cationic dyes," Carbohydrate Polymers, vol. 207, pp. 398-410, 2019.

[13] S. O.-B. Oppong, F. Opoku, and P. P. Govender, "Tuning the electronic and structural properties of $\mathrm{Gd}_{-} \mathrm{TiO}_{2}-\mathrm{GO}$ nanocomposites for enhancing photodegradation of IC dye: the role of $\mathrm{Gd}^{3+}$ ion," Applied Catalysis B: Environmental, vol. 243, pp. 106-120, 2019.

[14] Y. J. Zhang, M. Y. Yang, L. Zhang, K. Zhang, and L. Kang, “A new graphene/geopolymer nanocomposite for degradation of dye wastewater," Integrated Ferroelectrics, vol. 171, no. 1, pp. 38-45, 2016.

[15] S. Andini, R. Cioffi, F. Colangelo, T. Grieco, F. Montagnaro, and L. Santoro, "Coal fly ash as raw material for the manufacture of geopolymer-based products," Waste Management, vol. 28, no. 2, pp. 416-423, 2008.

[16] M. E. Alouani, S. Alehyen, M. E. Achouri, and M. Taibi, "Elaboration of inorganic polymer for removal of organic compound by dynamic column test," Moroccan Journal of Chemistry, vol. 7, pp. 10-16, 2019.

[17] M. El Alouani, S. Alehyen, M. El Achouri, and M. Taibi, "Removal of cationic dye-methylene blue-from aqueous solution by adsorption on fly ash-based geopolymer," Journal of Materials and Environmental Sciences, vol. 9, no. 1, pp. 32-46, 2018.

[18] M. El Alouani, S. Alehyen, M. El Achouri, and M. h. Taibi, "Preparation, characterization, and application of metakaolin-based geopolymer for removal of methylene blue from aqueous solution," Journal of Chemistry, vol. 2019, Article ID 4212901, 14 pages, 2019.

[19] M. EL Alouani, S. Alehyen, M. El Achouri, and M. Taibi, "Potential use of moroccan fly ash as low cost adsorbent for the removal of two anionic dyes (indigo carmine and acid orange)," Journal of Materials and Environmental Sciences, vol. 8, pp. 3397-3409, 2017.

[20] P. Duxson, The Structure and Thermal Evolution of Metakaolin Geopolymers, University of Melbourne, Melbourne, Australia, 2006.

[21] E. Papa, V. Medri, A. Natali Murri et al., "Characterization of alkali bonded expanded perlite," Construction and Building Materials, vol. 191, pp. 1139-1147, 2018.

[22] W. K. W. Lee and J. S. J. van Deventer, "Use of infrared spectroscopy to study geopolymerization of heterogeneous amorphous aluminosilicates," Langmuir, vol. 19, no. 21, pp. 8726-8734, 2003.

[23] M. Giannouri, T. Kalampaliki, N. Todorova et al., "One-step synthesis of $\mathrm{TiO}_{2} /$ perlite composites by flame spray pyrolysis and their photocatalytic behavior," International Journal of Photoenergy, vol. 2013, Article ID 729460, 8 pages, 2013.

[24] D. B. Istuque, L. Soriano, J. L. Akasaki et al., "Effect of sewage sludge ash on mechanical and microstructural properties of geopolymers based on metakaolin," Construction and Building Materials, vol. 203, pp. 95-103, 2019.

[25] L. Boudad, M. Taibi, A. Belayachi, and M. Abd-Lefdil, "Dielectric relaxation, electrical conductivity and optical studies of solid-state synthesized $\mathrm{EuCrO}_{3}$," Journal of Materials Science: Materials in Electronics, vol. 31, no. 1, pp. 353-360, 2020.

[26] J. Tauc, "Optical properties and electronic structure of amorphous Ge and Si," Materials Research Bulletin, vol. 3, no. 1, pp. 37-46, 1968.

[27] M. Edelmannová, L. Dubnová, M. Reli et al., "The role of fluorine in $\mathrm{F}-\mathrm{La} / \mathrm{TiO}_{2}$ photocatalysts on photocatalytic decomposition of methanol-water solution," Materials, vol. 12, no. 18, p. 2867, 2019.

[28] F.-E. N'faoui, J. Aride, A. Boukhari et al., "Crystal structure, spectroscopic, optical, thermal and magnetic studies of new orthoborate $\mathrm{Sr}_{2} \mathrm{Co}\left(\mathrm{BO}_{3}\right)_{2}$," Journal of Solid State Chemistry, vol. 283, Article ID 121167, 2020.

[29] X. Wang, S. Han, Q. Zhang, N. Zhang, and D. Zhao, "Photocatalytic oxidation degradation mechanism study of methylene blue dye waste water with $\mathrm{GR} / \mathrm{iTO}_{2}$," MATEC Web of Conference, vol. 238, p. 03006, 2018.

[30] S. K. Tammina, B. K. Mandal, and N. K. Kadiyala, "Photocatalytic degradation of methylene blue dye by nonconventional synthesized $\mathrm{SnO}_{2}$ nanoparticles," Environmental Nanotechnology, Monitoring \& Management, vol. 10, pp. 339-350, 2018.

[31] J. Lin, Z. Luo, J. Liu, and P. Li, "Photocatalytic degradation of methylene blue in aqueous solution by using $\mathrm{ZnO}-\mathrm{SnO}_{2}$ nanocomposites," Materials Science in Semiconductor Processing, vol. 87, pp. 24-31, 2018. 